\title{
Contesting the Culture Order: Contrastive Pragmatics in Action
}

\author{
Janet Holmes \\ Victoria University of Wellington, Wellington, New Zealand \\ janet.holmes@vuw.ac.nz \\ Bernadette Vine \\ Victoria University of Wellington, Wellington, New Zealand \\ bernadette.vine@vuw.ac.nz \\ Meredith Marra \\ Victoria University of Wellington, Wellington, New Zealand \\ meredith.marra@vuw.ac.nz
}

\begin{abstract}
Contrastive pragmatics encourages a focus on variation in the ways that different groups enact their distinctive cultural values and norms. In New Zealand, Pākehā (European-based) ways of doing things are the norm, taken-for-granted and rarely questioned or even noted unless someone "breaks the rules". For minority group members, however, including the indigenous Māori people, Pākehā norms are ever-present reminders of their non-dominant position. In the Māori workplace contexts that we have researched, awareness of these norms is particularly apparent and often attracts explicit comment. This paper explores the insights provided by comments from both Pākehā and Māori about workplace norms in New Zealand and the attitudes of some Māori employees to the hegemonic influence of Pākehā in workplace interaction, as well as providing some indications of seeds of change.
\end{abstract}

\section{Keywords}

workplace discourse - intercultural pragmatics - the culture order - sociopragmatic norms 
Acquiring sociopragmatic competence in one's first language(s) is generally an unconscious process which co-occurs with socialisation and acculturation into the community into which one is born. Along with developing competence in appropriate ways of interacting with others, we acquire familiarity with the values, beliefs, and attitudes encoded in our verbal repertoire. For majority group members whose language and culture dominate most social contexts, this process tends to be smooth and unproblematic. The experience of minority group members, however, is often rather different. As a result minority group members are typically more sensitive than majority group members to contrasting sociopragmatic norms.

In New Zealand, Pākehā (non-Māori, mostly European) ways of doing things are the norm, taken-for-granted and rarely questioned or even noted unless someone "breaks the rules". For minority group members, however, including the indigenous Māori people, Pākehā norms are ever-present reminders of their non-dominant position. ${ }^{1}$ In this article we examine evidence from New Zealand workplace interaction indicating the norms for Pākehā, as well as just how aware many Māori employees are of the pervasiveness and dominance of Pākehā ways of doing things, especially when these conflict with Māori cultural norms and values.

A large body of research has accumulated over more than thirty years in the area of contrastive pragmatics, addressing a wide range of scholarly issues, as well as the practical implications for learners from different sociocultural backgrounds. Much early work in this area focused on speech act realisations in different languages; however, more recent research has developed new theoretical concepts and frameworks, methodologies and preoccupations, such as modality and grammaticalisation, as well as continuing to be concerned with practical implications for learners (e.g., Aijmer, 2011). ${ }^{2}$

A strong early influence was the Cross-Cultural Speech Act Realization Project (Blum-Kulka and Olshtain, 1984; Blum-Kulka, House and Kasper, 1989), the questionnaires from which (including especially Discourse Completion Tests) were and continue to be (e.g., Béal, 20o9; Farnia, Buchheit and Salim,

1 Pākehā New Zealanders constitute 74\% (www.stats.govt.nz, 2013 census) while Māori constitute just $15 \%$ of the current New Zealand population. For a more nuanced account of Māori as an ethnic group which takes note of the importance of tribal affiliation see Diamond (2003: 25).

2 There is a very wide literature on pragmatics within intercultural communication more generally (see e.g. Holmes, 2018b; Higgins, 2007; Zhu and Kramsch, 2016), but here we have focused on research which fits under the specific heading of contrastive pragmatics. 
2010) extensively used to collect contrastive pragmatic data from a multitude of students from different sociocultural backgrounds (see, for example, articles in Kasper and Blum-Kulka, 1993; Gass and Neu, 1996; Schneider and Barron, 2008; Trosborg, 2010).

Critiques of Discourse Completion Tests (e.g., Beebe and Cummings, 1996; Turnbull, 2001) led to methodological innovations, including ways of collecting more authentic data (e.g., Spencer-Oatey and Xing, 200o; Morrison and Holmes, 2003). A range of different theoretical frameworks, including politeness theory (Fetzer, 2011) and appraisal theory (Becker, 2011) have proved fruitful in providing new insights in the area of contrastive pragmatics (see, for example, Pohl, 2004; Epstein, 2012). The relatively new area of Variational Pragmatics has also made an important contribution to contrastive pragmatics, using predominantly quantitative measures in the analysis of pragmatic variation (e.g., Schneider and Barron, 2008; Barron and Schneider, 2009), with an increasing number of practitioners drawing on naturally occurring speech rather than elicited responses (e.g., Jautz, 2013; Rüegg, 2014). Researchers engaged in the Variational Pragmatics enterprise have identified a range of contrasting sociopragmatic strategies in different varieties for expressing speech acts such as refusals, compliments, requests, expressions of gratitude, address terms, and so on.

One other well-established strand of sociopragmatic research has its roots in anthropological linguistics and sociolinguistics. Philips' (1972) research with the Warm Springs Indians, for instance, and Brice Heath (1982) illustrate this firmly qualitative approach. These researchers paid careful attention to explaining the cultural values that accounted for the culturally different interactional patterns which they described in detail. An important goal was to assist educators in understanding the classroom behaviour of children which did not conform to white American middle-class norms (see also Cazden, 2001). The predominant framework took white American middle-class norms for granted and little attention was paid to making explicit the assumptions and values which they embodied. Using a similar qualitative approach, in the analysis below we attempt to pay attention not only to minority group sociopragmatic norms but also to those of the majority group. Our focus is on what such an analysis suggests about the underlying cultural beliefs and values of different communities, and in particular those of many Māori and Pākehā in New Zealand.

Turning, then, to relevant New Zealand research, in addition to our own contribution which is well referenced in this paper, a number of earlier researchers have addressed such discursive issues as contrasting rules for speaking among different cultural groups (e.g., Salmond, 1974, 1975a; Metge and 
Kinloch, 1978), and the particular rhetorical strategies preferred by different groups (e.g., Thornton, 1985, 1999). Furthermore, Linda Tuhiwai Smith (1999) provides "an extensive critique of Western paradigms of research and knowledge from the position of an indigenous and 'colonised' Māori woman. She strongly advocates a more critical understanding of the underlying assumptions, motivations and values that inform research practices" (Wilson, 2001: 214). More recently Huygens further develops a critical stance in her discussion of the discursive resources involved in the ongoing crucial "dialogue between Māori and Pākehā about decolonisation work" (2006: 363). This literature, which largely originates from outside pragmatics, dovetails with the emerging trend for a metadiscursive and metapragmatic approach for exploring cultural norms (building on calls from Woolard, 1998 and Coupland and Jaworski, 2004). In our approach we consider norms that are recognised as salient above the level of awareness for participants, as well as those which are only visible through attention to practices. This decision matches our analytic prioritisation of naturally-occurring talk as data, but recognises that interactants often reference their ideologies and norms in their interactions.

Building on the existing research, we examine ways in which particular social values are both discussed and dynamically enacted by members of these two different ethnic groups, using evidence from workplace interaction for exemplification. We begin by briefly describing the culture order (Holmes, 2018a).

\section{The Culture Order}

The gradual colonisation of New Zealand by Pākehā immigrants throughout the 19th and 2oth centuries led to the imposition of Pākehā ways of doing things, reflecting European cultural norms and values in public and semipublic spheres, including the workplace. At the same time the cultural norms and values of the indigenous Mãori people tended to be overlooked or disregarded, if not actively repressed. The relative social status of the different groups resulted in a hegemonic relationship or an "order" manifested as sets of taken-for-granted unmarked sociocultural norms, expressed in different ways in different social contexts (Holmes, 2018a). The culture order thus comprises a hegemonic ideology promoting particular sociocultural values which influence the ways in which individuals discursively construct their social, ethnic, and gender identities in particular contexts in different societies. In general it is minority cultural group members who are most aware of the impact of the culture order (see Holmes, 2018a). Majority group members typically 
take them for granted and simply assume their ways of behaving are 'normal'. Consequently in most New Zealand workplaces, Pākehā norms prevail and workplace ideologies typically maintain and reinforce majority group cultural values. Māori and migrants working in these contexts are often very sensitive to contrasting cultural norms, and they sometimes attract overt comment (Holmes, Marra and Vine, 2011: Chapter 8; Holmes, 2018b).

A relatively small number of New Zealand workplaces can be described as 'ethnicised' Māori workplaces. ${ }^{3}$ Employees in ethnicised Māori workplaces are working for the benefit of the Māori indigenous minority in a variety of ways; the Māori culture order accounts for their ideological assumptions about appropriate behavior, and tikanga Mãori characterises many aspects of workplace interaction such as the way meetings are conducted, including the openings, turn-taking rules, acceptable ways of providing feedback, appropriate ways of doing leadership, and so on (see Holmes, Marra and Vine, 2011; Vine, 2019 for further discussion and detailed exemplification). When Pākehā employees work in such minority group contexts, their taken-for-granted majority norms often come into focus (Holmes, Marra and Vine, 2011; Holmes, 2018a). In what follows, we use a social realist approach as captured in our well-described model of the ways in which societal norms are negotiated in face-to-face interaction (e.g., Holmes, Marra and Vine, 2011). Many sociologists have noted that macro-level societal structures are instantiated at the microlevel through concepts such as agency (Giddens, 1984), habitus (Bourdieu, 1977), and transformation (Agha, 2003). Sociolinguists who espouse a social realist approach argue that societal norms constrain appropriate language use in different contexts, and focus on how they are negotiated in face-toface interaction (e.g., Bell, 2016; Coupland, 2016; Cameron, 20o9; Schnurr and Zayts, 2017; Wodak, 2008). Espousing this approach, we draw on material from our Wellington Language in the Workplace (LWP) database to identify some contrasting sociopragmatic norms which suggest that different priorities and values often obtain in Pākehā and Māori workplaces. ${ }^{4}$

3 See Holmes, Marra and Vine (2011:3); Schnurr, Marra and Holmes (2007); and Holmes (2018b) for further discussion.

4 Many of the examples have appeared in earlier work where they have been analysed from a different analytic stance. In this paper we have brought a new and nuanced approach to understanding cultural differences, synthesising our developing thinking in the area of contrastive pragmatics and offering illustration of the salience of subtle but distinctive norms and values. 
The methodology used by the LWP team has been thoroughly described in many publications (e.g., Holmes and Stubbe, 2003/2015; Holmes, Marra and Vine, 2011; Marra, 2008. See also www.victoria.ac.nz/lwp). Our basic methodology involves an ethnographic approach: following a period of participant observation of the daily interactions of employees by team members, we ask volunteers to record samples of their normal everyday workplace interactions, usually over a period of two to three weeks. This is followed by debriefing interviews to collect comments and reflections on this process. Where possible we video-record meetings of groups, using small cameras which are fixed in place, switched on, and left running for the whole meeting. Our policy is to minimise our intrusion as researchers into the work environment, all the while paying attention to the practices of the workplace community in which we are working and adjusting our methods in culturally sensitive ways. ${ }^{5}$ As a result, our database includes examples of workplace interaction which are as close to 'natural' as possible.

The LWP corpus currently comprises more than 2000 interactions, involving 700 participants from 30 different workplaces which include commercial organisations, government departments, small businesses, factories, building sites, and eldercare facilities. The data used in the analysis below draws from material recorded in meetings in professional white collar Māori and Pākehā workplaces, as well as ethnographic observation and interviews with key participants after the recording phase.

\section{$4 \quad$ Analysis}

Awareness of the existence of norms and sociocultural presuppositions is often brought more sharply into focus when they are transgressed or contested. Drawing on examples from our database, the analysis in this section provides evidence of both shared and contrasting sociopragmatic norms in some Māori and Pākehā workplaces; we focus on just two broad areas which represent relational and transactional workplace goals, namely sociability and (bureaucratic) accountability.

5 Marra (2008) outlines important adaptations to our methodology when working with participants in Māori workplaces. 


\subsection{Sociability}

Sociability is a highly-prized and recognisable value in both Māori and Pākehā worlds. We have extensive evidence from our analyses that people working together expect to engage in sociable talk at certain points in the working day: on first arriving at work, for instance, before and after meetings, and at work breaks such as morning tea and lunch (see, for example, Holmes, 2000; Holmes and Stubbe, 2003/2015; Holmes and Marra, 2004; Holmes, 2006; Holmes, Marra and Vine, 2011; Marra, 2012). When this expectation is unmet, New Zealanders tend to perceive the transgressor as unsociable and aloof.

As evidence of the salience of this shared norm, we offer an example involving a group from outside both communities, namely migrants from non-New Zealand backgrounds who are working in New Zealand professional contexts with the guidance of a mentor. In such cases the mentors' awareness of norms is often raised by the migrants' (generally unintentional) transgressions, offering a prime site for evidence of metapragmatic comments about values and practices. Excerpt 1 provides a typical example (see Vine, Holmes, Marra, 2012 and Holmes, 2015 for further examples). Isaac has not been interacting socially with other employees, so Leo gives him advice about the workplace norms.

Excerpt 1 [Transcription conventions can be found at the end of the article] Context: Isaac is a Chinese accountant; Leo is his workplace mentor.

1. Leo: try and integrate yourself more with everyone

2. $\quad$... but also the learning is

3. $\quad$ to sit with people at lunch time

4. and learn the language and listen to the jokes

5. $\quad$ and the and participate so sometimes ...

6. for your development I think

7. you need to work harder at that ...

8. $\quad$... just listen to people ...

9. and participate ...

Leo makes quite explicit the expectation that people in this workplace community will socialise at lunchtime, sharing jokes and exchanging stories. While different workplaces have somewhat different norms in this respect, social interaction during work breaks and small talk at the start of the day and before and after meetings is widely regarded as the norm. It is interesting that Leo uses very direct unattenuated linguistic forms, including imperatives, try and integrate yourself (line 1), learn the language and listen to the jokes (line 4), just listen to people ... and participate (lines 8-9), and need statements you need 
to work harder at that (line 7). While this is perhaps warranted by his role as mentor, it also suggests that Leo may be accommodating to his perceptions of Isaac's English proficiency level. Such direct language is rare in the New Zealand workplace between people who do not know each other well, suggesting that Leo regards it as important to very explicitly convey the message about the significance of sociability. ${ }^{6}$

Even when the participants are both New Zealanders, a breach of workplace sociability norms may attract attention, as excerpt 2 illustrates.

\section{Excerpt $2^{7}$}

Context: Jaeson (General Manager) with Rob (new Business Development Manager).

1. Jaeson: yeah I'm talking to Rob Bellinger

2. Rob: I- I broke it down [coughs]

3. what I what I figured was

4. what I thought was the most logical

5. Jaeson: what happened to the small talk?

6. Rob: [laughs] [laughs]: just I love the colour:

7. $\quad$ of what you're doing with your hair

8. $\quad$ //there [laughs]।

9. Jaeson: /[laughs] $] \backslash$ oh you're just

10. I mean you're so //straight into it you know like [laughs]\}

11. Rob: /[laughs] $\backslash \backslash$ um when we talked about [sighs]

12. the style of operation o- of the type of buyer ...

In this excerpt, Jaeson indicates that this is the beginning of a meeting by providing us (the researchers) with information about who he is talking to (line 1). Rob then launches straight into the meeting business (lines 2-4). Jaeson's reaction what happened to the small talk? (line 5) indicates clearly that Rob has transgressed a social norm, and Rob responds immediately by providing a parody of small talk (lines 6-8), drawing moreover on gender stereotypes by focussing on appearance (hair style) in order to increase the parodic effect of the response. Laughing, Jaeson then makes explicit how Rob has failed to conform to the norm: I mean you're so straight into it you know (line 10). Rob is relatively new to this workplace, but his unhesitating response in lines 6-8 indicates his awareness of the New Zealand sociocultural norm despite his initial lapse.

While this aspect of the sociability norm is a feature of the New Zealand culture order which is shared by the Māori and Pākehā participants in our data,

6 Isaac's responses to Leo's advice are explored in Vine, Holmes and Marra (2012).

7 This example is discussed in Schnurr and Holmes (2009) from a gender perspective. 
there are other aspects of sociability where sociopragmatic norms contrast. Insight into these aspects can often be provided by comments from employees on behaviours which they consider impolite or inappropriate. Māori typically put a great deal of effort into welcoming visitors as a sign of respect, while Pākehā are more likely to regard "dispensing with formalities" as desirable, emphasising collegiality and egalitarianism (Holmes, Marra and Vine, 2011; Holmes, Marra and Lazzaro-Salazar, 2017). ${ }^{8}$ Introducing yourself appropriately is a related feature of respect for your fellow workers. Excerpt 3 provides an account of an instance where a Pākehā co-worker flouted this widely accepted Māori norm.

\section{Excerpt 3}

Context: Māori organisation: Merimeri (Policy Analyst) and Inger (Research Analyst) discuss a Pākehā male's behaviour.

1. Inger: like um Jack getting Libby to come in

2. $\quad$ cos wasn't Jack originally

3. the one who was //supposed $\backslash$ to be?

4. Merimeri: /yep $\$

5. Inger: and then I didn't see anything of him

6. for a couple of months while I was //working on it।

7. Merimeri: /that's why $\backslash$ it cracks me up that he's like

8. well you should know me I'm Jack Standish

9. //it's like hello have you been to any meetings?।

10. Inger: /yeah [laughs] \\[laughs]

11. Merimeri: //don't think sol

12. Inger: /I just thought $\mid \backslash \mathrm{I}$ thought

13. it was was kind of rude just coming in

14. not even saying hi- you know

15. introducing himself or saying hello

16. $\quad$ cos he'd never met me before + obviously ++

In this excerpt, Inger and Merimeri jointly and collaboratively construct an evaluation of the behaviour of Jack, a more senior person from another organisation who is supposed to be supporting their work. Inger first complains that despite the fact that he was supposed to be assisting her, she did not see Jack while she was working on the issue, only his subordinate Libby (lines 1-3, $5^{-6)}$. Merimeri adds that his behaviour cracks me up (line 7) as he has not been attending meetings (lines 9, 11), a complaint that she phrases as a satirical

8 See also Spencer-Oatey and Xing (2000) on a similar contrast between British and Chinese meeting welcoming behaviours. 
question hello have you been to any meetings? (line 9). Inger then elaborates, describing how Jack just came in and did not greet her or introduce himself although he had not met her before (lines 12-16), behaviour that she labels kind of rude (line 13). Merimeri infers from his attitude that he assumes they know him: he's like well you should know me I'm Jack Standish (lines 8-9), an attitude which Inger's subsequent condemnation clearly implies is arrogant. Failing to greet and introduce yourself in such a context would generally be regarded as a breach of Māori norms which place great value on nurturing relationships, a breach of which Jack seems unaware, or to which he is perhaps indifferent. ${ }^{9}$

Another important area of sociability where tikanga Mãori differs in degree from Pākehā norms involves what is considered an appropriate way of hosting guests or, in business contexts, clients (Salmond, 1974; Metge, 1995; Smith, 1999; Holmes and Marra, 2011). The roots of appropriate hospitality behaviour lie deep in Māori culture; the concept manaaki ki te tangata (share and host people, be generous) embraces all aspects of welcoming outsiders into a group including a formal welcome, appropriate karakia/prayers and providing food and drink for guests "after what might be seen as everyday, unremarkable events when viewed through a Western lens" (Marra, King and Holmes, 2013: 50). Marra, King and Holmes (2013) analyse in detail a complex instance of intercultural misunderstanding deriving from a Pākehā staff member's perceived questioning of the provision of hospitality towards clients (a lunch) in a Māori workplace. The paramount importance of appropriate hosting is clearly a core concern within the Māori business world, but not all Pākehā understand its fundamental significance which derives from cultural values deeply embedded in Māori culture.

\subsection{Performing Accountability}

Turning to the issue of accountability, the presuppositions and norms of the dominant Pākehā culture order come into sharp focus. Our data on this aspect of contrastive pragmatic behaviours comes from Pākehā working in Māori organisations, as well as from Māori working in organisations which purport to be bicultural, but where Māori perceptions identify some interesting discursive faultlines (Menard-Warwick, 2013). Interaction in such workplaces provides interesting evidence of the pervasiveness of the Pākehā culture order, and in particular of areas where Māori and Pākehā priorities sometimes differ.

9 This interaction can also be regarded as evidence of how minority group members may build solidarity by critiquing the "other", an observation we owe to an anonymous reviewer. 
Excerpt 4 illustrates how different cultural expectations can lead to misperception and misinterpretation. As background it is important to note that negative Pākehā stereotypes of minority groups include a perception of Māori as financially incompetent, and as often wasting public (taxpayers') money on activities not judged economically worthwhile by the business world. In excerpt 4, Gretel, a senior Pākehā Manager in a Māori organisation, indicates her awareness of this stereotype.

\section{Excerpt 4}

Context: Māori production company: Gretel is discussing strategic and financial issues with Yvonne, the Māori Managing Director.

1 Gretel: this is government it's the Ministry's money

$2 \quad$ and if people could actually view that rather dimly

3 because these two women who were doing (website) stuff

4 they were going to take them out for a meal

$5 \quad$ and Raewyn said oh we could take them

$6 \quad$ I've got a half price thing we could take them

7 to the seafood buffet at the Sheraton

8 and I said look I know it's probably cheaper

9 but I don't want you to take them there

10 you know imagine what it would look like

11 if someone from the Ministry saw you

$12 \quad$ wining and dining with some clients

13 on the Ministry's dollar at the Sheraton

Here Gretel clearly and explicitly identifies the core issue - Pākehā prejudice and negative stereotypes of Mãori mean that a legitimate expression of gratitude for work well done will be viewed as wasting government money if money is spent at the prestigious Sheraton Hotel Restaurant, even though they were planning to use a half price thing (line 6) to reduce the cost. And Gretel concludes by succinctly summing up the issue: imagine what it would look like if someone from the Ministry saw you wining and dining with some clients on the Ministry's dollar at the Sheraton (lines 10-13).

Yvonne, the Managing Director, is very conscious of the issue and elsewhere states quite unequivocally her awareness that their business activities "are constantly subject to an ethical microscope reserved for Māori organisations who are expected to be 'whiter than white' to counter negative perceptions in a competitive mainstream industry" (Marra, 2005). As Marra (2005) notes, to escape such criticism Māori companies must deliver on time, meet deadlines, keep to budget, and act in an exemplary manner in all respects: 
Yvonne is very aware that behaving appropriately involves Māori businesses being super-careful about expenditure on accommodation and travel, especially when government contract money is involved, and in general it is crucial to avoid providing any basis for public comment or complaint.

From a Māori perspective, there are different rules for majority and minority groups in this respect, and Māori business people are typically very sensitive to the danger of providing ammunition to further fuel negative perceptions and ethnic prejudice. Measuring up to Pākehā expectations of accountability is the bottom line. Gretel's explicitness on this issue in a Māori workplace indicates not only that she shares her Māori colleagues' sensitivity to negative Pākehā perceptions, but that she is also confident that she is perceived by Yvonne, her Māori boss, as sympathetic to Māori norms in this area.

In another example of the importance of orienting to accountability for Māori organisations (discussed in detail in Holmes and Stubbe, 2015: 42-43), Jan, a Pākehā branch manager uses indirect strategies to suggests that Heke, the policy manager, needs to crack the whip a little with staff who have been under-performing. When he responds by suggesting they may need to work evenings and weekends, Jan suggests that he should not go overboard and refers to the fact that they belong to an officially "family-friendly workplace" to support her point (Holmes and Stubbe, 2015: 43). In this example, contrary to patterns of rhetorical indirectness often associated with Māori discourse (Salmond, 1975b), it is Heke, the Māori manager, who, using direct and forceful language, orients explicitly to the Pākehā demand for hard work and accountability. By contrast, Jan, the Pākehā manager adopts indirect sociopragmatic strategies to back-pedal both in terms of content and discursive style, and it is she who draws attention to the importance in a Māori organization of taking account of family values. She skillfully opposes Heke's suggestion that he take a tough line, while simultaneously indicating that she appreciates his good intentions. She achieves this by using a range of linguistic devices which serve as softeners or hedges, such as the pragmatic particles you know, sort of, Imean, repetition, and echoing devices (see Holmes and Stubbe, 2015: 43).

The bureaucratic processes associated with accountability are often brought sharply into focus in bicultural workplaces where there is an avowed commitment to take account of both Māori and Pākehā values and cultural norms. The next two longer excerpts hone in more specifically on evidence of the complex ambivalence in stance provided by the reflections of Māori employees in such workplaces. The excerpts involve interactions between two Māori men 
who are evaluating funding applications from providers of vocational training aimed at assisting disadvantaged Māori students.

It is clearly the case that although positive outcomes for Māori are an explicitly stated goal, Pākehā bureaucracy prevails in such workplaces, namely what one employee, Aidan, describes as hōhä: [tiresome] paperwork eh (Holmes and Marra, 2002: 384). Essentially, Māori are required to meet Pākehā standards even in the interests of providing positive results for Māori. Excerpt 5 provides an example of these Māori employees' perspective on the ways in which a Māori group from a different region manage these complex demands.

\section{Excerpt 5}

Context: Vincent and Aidan are discussing proposals regarding material for assessing Māori language competence.

1. Vincent: um all this stuff is in Māori bro

2. Aidan: oh yeah I did read it I did read it

3. Vincent: [laughs] I'm gonna take //photo/copies of that ...

4. Aidan: /yeah $\backslash$

5. Aidan: but that's what's good about some of these things

6. $\quad$ is the forms that come (with them)

7. Vincent: [laughs] yeah $/ /[$ laughs $] \backslash$

8. Aidan: /you can rip them out eh $\backslash$ like for the capability stuff and + recording

9. Vincent: you're a prof bro

10. Aidan: yeah

11. Vincent: $\mathrm{um}+++$ yeah + evidence of application ...

12. lot of self-assessment stuff in there +

13. performance test examination and stuff

14. they even do that I don't know how they do it +

15. be pretty amazing to actually visit there eh

16. and see how they do stuff eh

17. Aidan: oh I've been up there

18. Vincent: amazing?

19. Aidan: yep

20. Vincent: is that you know is it what they write is what they do?

21. Aidan: yeah yeah they do more than that mate [tut]

22. they're a typical Māori organisation

23. they sit up till three in the morning all in a big group

24. fucking nutting things out +

25. [in Māori]: kōrero kōrero kōrero: [talking] 
There is much that could be discussed in this rich excerpt, ${ }^{10}$ but we focus here on evidence relevant to the identification of contrasting sociopragmatic strategies. The fact that the material they are assessing is written in Māori is noteworthy to Vincent (line 1), and he clearly regards it as exemplary I'm gonna take photocopies of that (line 3). Aidan explicitly agrees and elaborates on the extent to which the material provided by this group can be treated as models: you can rip them out eh like for the capability stuff and recording (line 8); and Vincent proceeds to list further evidence in some detail (lines 11-13). The two young men are united, then, in admiration of the material which the Māori applicants have provided to fulfil the bureaucratic requirements of the Pākehā funding system.

Vincent then introduces the matter of process: be pretty amazing to actually visit there eh and see how they do stuff eh (lines 15-16), speculating whether what they write is what they do (line 20), i.e. they speak in fluent Māori and so they can produce the required documents in te reo Māori. Aidan provides a graphic description of the canonical Māori process for those working in $a$ typical Māori organisation (line 22) who need to discuss a complex matter: they sit up talking (kōrero kōrero kōrero) until they have reached agreement (lines 23-25). This process is a traditional one, firmly rooted in Māori culture which values reaching consensus only after everyone has had an opportunity to fully express their views (Metge, 1995; Mead, 2016: 170). In sum, the excerpt vividly describes the ways in which Māori discourse strategies, embodying values of respect for others and the high value placed on reaching consensus, are employed in meeting the demands of the overarching Pākehā culture order in order to obtain funding to further Māori goals.

However, a little later in the interaction, there are indications of some degree of reservation, and perhaps kernels of growing discontent, in the evaluations by these young Māori of the extent to which their elders are prepared to conform to the bureaucratic demands of Pākehā accountability.

\section{Excerpt 6}

Context: Vincent and Aidan discussing proposals regarding material for assessing Māori language competence.

1. Aidan: they're [in Māori]: tūturu [truly] Māori:

2. but they're always trying [drawls]: to:

3. $\quad$ //filter their be Pākehā

10 See Holmes and Stubbe (2015, Chapter 7) for a discussion of discourse evidence of solidarity between these interactants, for instance the issue of "agency dilemma" (Bamberg, 2011) is another point which we do not have space to pursue here. 
4. Vincent: /be Pākehā|l

5. Aidan: //so when they $\backslash$ put their stuff in like this

6. Vincent: /I hate it \।

7. Aidan: they put- try and put it in what we want to read ...

8. Vincent: I was wondering whether they're trying to mask

9. what they can't [laughs]: do: er Pākehā fashion

10. you know like mask it by using all this upbeat language

11. (because) they actually haven't worked out

12. how they're going to do it

13. or the strategies they've got in place

14. or the methods and all that sort of stuff ...

15.

16. Aidan: [discussion continues for several minutes]

17.

18. in reality though mate there's um ++ so few Māori organisations

19. that are onto it + that are really onto it and deliver good training

19.
20. that's the thing that's blown me away actually +

21. [tut] and the ones that are are more actually more Pākehā

22. than they are Māori

This harsh critique of a Māori organisation by these two young Māori men makes a number of telling points. Aidan begins by stating explicitly that the organisation is tüturu [truly] Mãori, a relatively rare phenomenon in their experience and in New Zealand generally. Nevertheless, he proceeds to criticise them as trying to ... be Pākehā (lines $2-3$ ) and questions their integrity by suggesting they put into their application what we want to read (line 7). Vincent develops the critique by wondering if they mask what they can't do (lines 8-9) which he describes as a Pākehā ploy (line 9), using upbeat language (line 10) to conceal the fact that they haven't worked out the strategies they will use to deliver what they have promised (lines 11-14). Aidan then makes the point that there are so few Māori organisations that ... deliver good training (line 16-18), and, tellingly, he suggests, the ones that do are more Pākehà than they are Mãori (lines 21-22).

Discursively, there are many indications that these two young men are close colleagues on the same wavelength as they express their dissatisfaction with the conformist behaviour evident in the Māori application that they are evaluating (see Holmes and Stubbe, 2015: 160-162). The critique is collaboratively constructed, with overlapping utterance completions (line 4) and supportive comments (line 6). They elaborate and build on each other's arguments throughout. Aidan uses mate (line 16) in this excerpt, and in excerpt 5 bro (line 1), and the affiliative pragmatic particle $e h$ is used by both (lines $8,15,16$ ). 
This jointly constructed discourse contrasts markedly with the laconic interactions between Aidan and Hugh, a Pākehā colleague in the same organisation which is analysed in detail in Holmes and Stubbe (2015: 157-160). In a postrecording interview Aidan comments on what he describes as a Pākehä trick in terms of communication of using a thousand words to explain what you could explain in five, a strategy which Aidan labels as a powerplay intended to bamboozle with words and jargon (Holmes and Stubbe, 2015: 158).

These two young Māori men thus explicitly articulate dissatisfaction with the requirements of Pākehā bureaucracy, and especially with those Māori organisations who have developed discourse strategies for playing the game in order to succeed in a Pākehā-dominated society. They do acknowledge, however (not shown in these excerpts), that they understand why the organisation has done this as they themselves engage in similar behaviour.

The majority of our recordings of Māori working in government departments or Pākehā organisations provide extensive evidence that these employees are very familiar with the expectations and norms regarding appropriate ways of interacting and completing their job requirements in a society governed by the Pākehā culture order. Occasionally, however, we get a glimpse of their perceptions of the issues constantly encountered by Mãori working in such contexts. Excerpt 7 illustrates the cynicism of more experienced, politically sophisticated Māori government employees who have no illusions about the challenges facing Māori in a Pākehā-dominated society.

\section{Excerpt 7}

Context: A Māori group within a government organisation are discussing lack of progress on an issue that they recognise is beset with political tensions.

$\begin{array}{lll}1 & \text { Tracey: } & \begin{array}{l}\text { it's always been like that though eh }(\text { ) } \\ \text { //I don't know } \backslash \text { how many reviews there's been }\end{array} \\ 3 & \text { Hera: } & \begin{array}{l}\text { /it's a political issuell } \\ \text { just like the Māoris }\end{array} \\ 4 & \text { Ripeka: } & \begin{array}{l}\text { [people smile and look amused] } \\ \text { it's a political issue not a not an issue }\end{array} \\ 5 & \text { Hera: } & \begin{array}{l}\text { it's not it's not it's got nothing to do with logic } \\ 6\end{array} \\ 7 & \text { Tracey: } & \text { no }\end{array}$

Ethnicity is explicitly invoked as the women use humour to express their rejection of the bureaucratic demands of the Pākehā organisation. ${ }^{11}$ In lines 1-2, Tracey refers to a situation they have been discussing which keeps surfacing

11 This discussion draws on Holmes (2018b). 
and attracting criticism. The standard political response in such a situation is to set up a review. Hence her comment I don't know how many reviews there's been (line 2). Hera provides a plausible explanation it's a political issue (line 3), implying that the lack of progress has nothing to do with logic, a point she articulates explicitly in lines $5^{-6}$. In between these comments Ripeka inserts an ironic remark just like the Mãoris (line 4), drawing on a familiar negative stereotype of Māori style in which, in the New Zealand popular imagination, political tension and fractious argument are considered to be major features of Māori behaviour. Ripeka's “double voicing” (Bakhtin, 1994) clearly emphasises her ironic intent.

These negative allusions can be derived without any effort by the women at the meeting for whom such a remark serves as a compressed shorthand for the dominant group's predictable prejudices about Māori. As members of the minority group, our Māori participants are sensitive to potential discrimination, and very aware of the pervasiveness of unequal treatment (Holmes and Hay, 1997). This illustrates well how interpretation of such remarks is extremely context-sensitive. Ripeka's remark is perfectly acceptable when made by a Māori person among other Māori, where it clearly signals in-group solidarity and shared knowledge of damaging racist stereotypes. Uttered by a non-Māori person in the same context, it would almost certainly be interpreted as insulting and racist.

This rather cryptic exchange, then, from the perspective of a Pākehā listener (or reader), provides a nice illustration of a culturally interesting feature which often characterises Māori informal interactions. The shared subtle understandings between these Māori employees concerning Pākehā perceptions of Māori mean that they do not need to explicitly spell out their meanings. A similar feature characterises some Māori narratives (Holmes, 1998; Holmes, Marra and Vine, 2019). These relatively senior women working in a government department have many years of experience in negotiating the channels of communication within their government sector. They are well aware that Pākehā norms prevail in this context and how this impacts on their activities, as well as how Māori are perceived.

In addition to the allusive, implicit meanings which characterise this exchange, Holmes (2018b) points out that this excerpt illustrates another interesting area of contrastive pragmatics. As noted, Ripeka uses cynical humour to reference the constant negative stereotyping experienced by Māori in a Pākehā-dominated society. "By contrast, there are no such examples, nor even a hint of humour in the Pākehā meetings referring to their position as members of the dominant culture" (2018b: 336-337). It is simply taken-for-granted and does not require or attract comment. 
Contrastive pragmatics encourages a focus on variation in the ways that different groups enact their distinctive cultural values and norms. The analyses in the previous section have illustrated a number of areas of contrasting ways of "doing things with words" (Austin, 1962), indicating an orientation to particular ideologies, values and beliefs.

The first two examples demonstrate the importance that New Zealanders place on social talk at work. Engaging in small talk at appropriate times throughout the day is regarded as a sign of willingness to be collegial and positive. Hence in excerpt 1, Leo, Isaac's mentor, instructs him very explicitly on the importance of contributing to the lunchtime conversations, ostensibly to help with his language learning, but importantly so that Isaac will be perceived positively by New Zealand colleagues. We have abundant evidence from the feedback of those on our Communication Skills for Professional Migrants course (Prebble, 2007), that this feature of interaction in New Zealand workplaces is alien and puzzling to those from other countries with different cultural values, such as China and Germany (Holmes and Riddiford, 2009). In these cultures the emphasis is on demonstrating that one is hard working and committed to meeting transactional goals (cf. Clyne, 1994). Social talk is regarded as a waste of time. Consequently, the emphasis on social talk in New Zealand workplaces is bewildering. To those from cultures where power and status is important, the significance of New Zealand values such as egalitarianism and collegiality is not apparent. The informality which characterises New Zealand interaction in a wide range of contexts (Holmes, Marra and Vine, 2012) is thus regarded with suspicion by those from cultures with different priorities.

In addition to work breaks, such as morning tea and lunch, social talk is also characteristic of the interaction before the meeting in every workplace where we recorded large meetings. Clearly in these contexts social talk is regarded as obligatory. Excerpt 2 demonstrated that this norm is also relevant in small group and one-to-one meetings in some teams. Hence Rob's launch straight into business is challenged by Jaeson as unorthodox. At the societal level, the organisational level, and the team level then (see our model: Holmes, Marra and Vine, 2011: 19) there is evidence that a perceived commitment to an egalitarian ideology plays out in the significance attached to engaging in polite social interaction in a wide range of contexts, including the workplace.

Excerpt 3 focused on an area of contrasting sociopragmatic norms between Māori and Pākehā in New Zealand. As a result of the dominant egalitarian ideology, informality is favoured in many contexts where Māori values regard expressing respect for others as more important. As we have documented in 
detail (e.g., Holmes, Marra and Vine, 2011), most New Zealand workplaces in our dataset tend to dispense with formalities even in large meetings, for instance, starting with the briefest of phrases such as let's go, whereas Māori meetings typically open with a karakia or prayer and an explicit welcome of some kind. Hence the discussion between Merimeri and Inger in excerpt 3 indicates their scorn for the practice of walking in without introducing oneself as illustrated by Jack Standish. From a Māori perspective this can be seen as disrespectful and even insolent behavior.

When considering the issue of performing accountability, the presuppositions and norms embedded in the Pākehā culture order can lead to misperception and misinterpretation. Negative Pākehā stereotypes of minority groups include a perception of Māori as financially incompetent, and as often wasting money on activities not judged economically worthwhile. In excerpt 4 , Gretel, a senior Pākehā Manager in a Māori organisation, indicates her awareness of this stereotype, and describes her advice to staff to protect themselves from the criticism that may arise from a misperception that they are wastefully spending public money, although they planned to actually save money by using a discount. Excerpt 5 also raises the issue of performing accountability as defined by the bureaucratic requirements of the Pākehā-defined evaluation system within which Vincent and Aidan operate. They express admiration for members of a Māori organisation who have mastered the complex administrative system, and especially at the fact that this organisation uses traditional Māori processes of talking through to consensus, no matter how long that takes. However, excerpt 6 indicates the development of a more critical stance as the two men bring a Māori perspective to bear on the extensive form-filling required. They express suspicions that the group are using Pākehā strategies of providing what we want to read and using obfuscating language to conceal the fact that they have not yet thought through the steps needed to achieve their goals. These excerpts thus illustrate the ambivalence sometimes apparent in the attitudes of young Māori working within the Pākehā system which is dominated by values that seem to conflict with those of their own cultural group.

The final example provides evidence of a similar but more confident critique of Pākehā-dominated bureaucracy expressed by experienced employees in another government department. Excerpt 7 features an all-Māori team who are well accustomed to the compromises required of Māori working within the Pākehā culture order. Their response is ironic cynicism, indicating awareness of the fact that Māori priorities tend to be overlooked and hinting furthermore that Māori are generally regarded negatively and perceived as argumentative. This excerpt, then, suggests the existence of pockets of implicit challenge which are only rarely apparent in our recorded data, perhaps because Pākehā 
workplaces (where the majority of our recordings have been collected) are not perceived as the appropriate place to express criticism, however allusively.

\section{$6 \quad$ Conclusion}

Analysing informal conversations between young Pākehā and between young Māori, Holmes and Hay (1997: 135) noted:

Minority groups are much more sensitive to areas of difference between their norms and those of other groups than are those in power. Powerful groups take their hegemonic values and associated norms for granted; they are "given", assumed, unquestioned and even unconscious. Members of minority groups are generally much more attuned to areas of cultural difference between their own patterns of interaction and those of the majority group.

The analysis in this paper suggests some contexts in which Pākehā sociopragmatic norms (usually simply assumed) are raised to consciousness, as well as supporting the point that minority group members are typically most sensitive to areas of cultural contrast.

As so often in sociopragmatics, norms come most sharply into focus when they are breached. Hence Leo's advice to Isaac in excerpt 1 is a result of noting Isaac's failure to engage socially in social contexts where this is regarded as obligatory. Leo's role as mentor licenses him to give such advice quite explicitly. In excerpt 2, Jaeson's reaction is clearly intended to be humorous, yet nonetheless it draws attention to Rob's breach of the usual way of beginning a meeting in his organisation even when only two people are involved.

Our analysis suggests that a second important context in which Pākehā sociopragmatic norms are raised to awareness is in contexts where, unusually, the Māori culture order is more relevant than the Pākehā culture order. In workplaces where Māori ways of doing things are relevant, breaches, especially by Pākehā employees, attract attention (see Holmes, Marra and Vine, 2011). Merimeri's criticism of the Pākehā who failed to introduce himself (excerpt 3) illustrates this point well.

What this suggests is that one important way of raising awareness of contrasting sociopragmatic norms is to immerse Pākehā in Māori workplaces where it is Pākehā sociopragmatic norms and their associated values that are marked. Post-recording interviews with Pākehā senior managers in ethnicised Māori workplaces vividly demonstrated how much they had learned as a 
result of this process. One commented, for example, I was challenged, it caused me to rethink and reflect ... it was a humbling experience. He reflects that he could so easily have been regarded as a brash Päkehā that knew everything if he had not been prepared to observe, listen, and learn to appreciate different ways of doing things. ${ }^{12}$ Holmes, Marra and Vine (2011) provide additional examples of Pākehā who describe the challenges and complexities of their position as majority group members in minority workplaces, and of their raised awareness of contrasting sociopragmatic norms, such as not asserting expertise until asked to do so, and not interrupting when others are speaking.

A humorous discussion collected ten years later in an organisation where Māori tikanga is respected provides a context where attitudes to Pākehā can be more explicitly articulated. The confidence in their own procedures evident in the interactions between Māori in such workplaces is inevitably tempered by awareness of the judgement of the outside world as illustrated in excerpt 4 . However, as discussed in Holmes, Marra and Vine (2011, 2019), the fact that Pākehā attitudes and behaviours are made the butt of humour, even in a formal meeting, suggests a growing confidence in resisting and contesting culturally insensitive norms. As one of the group wittily remarks, Māori is the new black eh? (Holmes, Marra and Vine, 2011: 103), a comment that signals awareness of the importance of paying more than lip-service to biculturalism in a society where the Māori culture order has been repressed or ignored for more than 150 years.

Finally our analyses provide evidence that Pākehā employees working in Māori workplaces tend to develop sensitivity to Māori norms and values, and that Māori employees are increasingly questioning and critiquing Pākehā ways of doing things. We have identified this trend especially in workplaces with claims to being bicultural (Holmes and Vine, forthcoming). As growing numbers of Māori take on senior roles in organisations dominated by Pākehā, awareness of contrasting sociopragmatic norms seems destined to increase, a trend which we would argue will enhance the richness and diversity of workplace interaction in New Zealand.

\section{Transcription Conventions}

[laughs]:: Paralinguistic features and editorial information in square brackets; colons indicate beginning and end where appropriate

12 Māori norms typically involve learning by observation rather than explicit teaching (Metge, 1995); this was evident from accounts provided in our post-recording interviews. 


$\begin{array}{ll}+ & \text { Pause of up to one second } \\ \ldots /|\ldots \ldots| & \text { Simultaneous speech } \\ \mid \ldots \ldots . . \ldots \ldots & \\ (\quad) & \text { Unclear utterance } \\ - & \text { Utterance cut off } \\ \ldots & \text { Section of transcript omitted } \\ {[\text { tut }]} & \text { Bilabial/alveolar/dental click }\end{array}$

Names of workplace participants and workplaces are pseudonyms

\section{Bio Notes}

Janet Holmes is Emeritus Professor of Linguistics and Associate Director of the Wellington Language in the Workplace Project at Victoria University of Wellington, New Zealand (www.victoria.ac.nz/lwp). She has published on many aspects of sociolinguistics, including workplace discourse, New Zealand English, and language and gender.

Bernadette Vine is a Researcher on the Wellington Language in the Workplace Project at Victoria University of Wellington, New Zealand. Bernadette's research interests include workplace communication, leadership and New Zealand English.

Meredith Marra is Director of the Wellington Language in the Workplace Project at Victoria University of Wellington, New Zealand. She has been researching workplace discourse for 20 years, analysing the language of business meetings, (im)politeness, humour and various aspects of identity.

\section{Acknowledgements}

We gratefully acknowledge the participants who volunteered their words and thoughts, the transcribers for their technical work, and the funders who financially supported the data collection from which our extracts have been taken, notably a Marsden grant administered by the Royal Society of New Zealand. We thank Emily Greenbank for assistance with the literature review and the Victoria University of Wellington Discourse Analysis Group for workshopping with us the examples used in the analysis, thus providing helpful warranting to support our claims. 


\section{References}

Agha, Asif. 2003. The social life of cultural value. Language \& Communication 23: 231-273.

Aijmer, Karin (ed.). 2011. Contrastive Pragmatics. Amsterdam: John Benjamins.

Austin, John L. 1962. How to do Things with Words. Oxford: Clarendon Press.

Bakhtin, Mikhail. 1994. Double-voiced discourse in Dostoevsky. In: Pam Morris (ed.), The Bakhtin Reader: Selected Writings of Bakhtin, Medvedev, Voloshinov. London: Edward Arnold, 102-111. (Original published 1963).

Bamberg, Michael. 2011. Who am I? Narration and its contribution to self and identity. Theory \& Psychology 21: 3-24.

Barron, Anne and Klaus P. Schneider. 20og. Variational pragmatics: Studying the impact of social factors on language use in interaction. Intercultural Pragmatics 6(4): $425^{-442 .}$

Béal, Christine. 20o9. Keeping the peace: A cross-cultural comparison of questions and requests in Australian English and French. Multilingua 13(1-2): 35-58.

Becker, Annette. 2011. Modality and ENGAGEMENT in British and German political interviews. In: Karin Aijmer (ed.), Contrastive Pragmatics. Amsterdam: John Benjamins, $5^{-22 .}$

Beebe, Leslie M. and Martha Clark Cummings. 1995. Natural speech act data versus written questionnaire data: How data collection method affects speech act performance. In: Susan Gass and Joyce Neu (eds.), Speech Acts Across Cultures: Challenges to Communication in a Second Language. Berlin: Walter de Gruyter, 65-86.

Bell, Allan. 2016. Succeeding waves: Seeking sociolinguistic theory for the twenty-first century. In: Nikolas Coupland (ed.), Sociolinguistics: Theoretical Debates. New York: Cambridge University Press, 391-416.

Blum-Kulka, Shoshana, Juliane House, and Gabriel Kasper (eds.). 1989. Cross-Cultural Pragmatics: Requests and Apologies. Norwood, N.J.: Ablex.

Blum-Kulka, Shoshana and Elite Olshtain. 1984. Requests and apologies: A crosscultural study of speech act realization patterns (CCSARP). Applied Linguistics 5(3): 196-213.

Bourdieu, Pierre. 1977. Outline of a Theory of Practice. Cambridge: Cambridge University Press.

Brice Heath, Shirley. 1982. What no bedtime story means: Narrative skills at home and school. Language in Society 11(1): 49-76.

Cameron, Deborah. 2009. Theoretical issues for the study of gender and spoken interaction. In: Pia Pichler and Eva M. Eppler (eds.), Gender and Spoken Interaction. London: Palgrave Macmillan, 1-17.

Cazden, Courtney B. 2001. Classroom Discourse:The Language of Teaching and Learning, 2nd edition. Portsmouth, N.H.: Heinemann. 
Clyne, Michael. 1994. Inter-Cultural Communication at Work: Discourse Structures across Cultures. Cambridge: Cambridge University Press.

Coupland, Nikolas. 2016. Sociolinguistics: Theoretical Debates. New York: Cambridge University Press.

Coupland, Nikolas and Adam Jaworski. 2004. Sociolinguistic perspectives on metalanguage: Reflexivity, evaluation and ideology. In: Adam Jaworski, Nikolas Coupland and Dariusz Galasinski (eds.), Metalanguage: Social and Ideological Perspectives. Berlin: Mouton De Gruyter, 15-51.

Diamond, Paul. 2003. A Fire in your Belly: Māori Leaders Speak. Wellington: Huia.

Epstein, Charlotte. 2012. Norms. In: Rebecca Adler-Nissen (ed.), Bourdieu in International Relations: Rethinking Key Concepts in IR. New York: Routledge, 183-196.

Farnia, Maryam, Lyn Buchheit and Shahida Banu binti Salim. 2010. "I need to talk to you" - A contrastive pragmatic study of speech act of complaint in American English and Malaysian. Language, Society and Culture 30: 11-24.

Fetzer, Anita. 2011. Challenges in contrast: A function-to-form approach. In: Karin Aijmer (ed.), Contrastive Pragmatics. Amsterdam: John Benjamins, 73-96.

Gass, Susan and Joyce Neu (eds.). 1996. Speech Acts Across Cultures: Challenges to Communication in a Second Language. Berlin: Walter de Gruyter.

Giddens, Anthony. 1984. The Constitution of Society. Outline of the Theory of Structuration. Cambridge: Polity.

Higgins, Christina (ed). 2007. A closer look at cultural differences: 'Interculturality' in talk in interaction. Special Issue of Pragmatics 17(1).

Holmes, Janet. 1998. Narrative structure: Some contrasts between Māori and Pākehā story-telling. Multilingua 17: 25-57.

Holmes, Janet. 200o. Doing collegiality and keeping control at work: Small talk in government departments. In: Justine Coupland (ed.), Small talk. Harlow: Pearson, $3^{2-61 .}$

Holmes, Janet. 2006. Gendered Talk at Work: Constructing Gender Identity through Workplace Discourse. New York: Blackwell.

Holmes Janet. 2015. Joining a new community of workplace practice: Inferring attitudes from discourse. In: Elke Stracke (ed.), Intersections: Applied Linguistics as a Meeting Place. Newcastle-upon-Tyne: Cambridge Scholars Publishing, 2-21.

Holmes, Janet 2018a. Negotiating the culture order in New Zealand workplaces. Language in Society 47:33-56.

Holmes, Janet. 2018b. Intercultural communication in the workplace. In: Bernadette Vine (ed.), The Routledge Handbook of Language in the Workplace. Abingdon: Routledge, 335-347.

Holmes, Janet and Jen Hay. 1997. Humour as an ethnic boundary marker in New Zealand interaction. Journal of Intercultural Studies 18(2): 127-151. 
Holmes, Janet and Meredith Marra. 2002. Humour as a discursive boundary marker in social interaction. In: Anna Duszak (ed.), Us and Others: Social Identities Across Languages, Discourses and Cultures. Amsterdam: John Benjamins, 377-40o.

Holmes, Janet, and Meredith Marra. 2004. Leadership and managing conflict in meetings. Pragmatics 14(4): 439-462.

Holmes, Janet, and Meredith Marra. 2011. Relativity rules: Politic talk in ethnicised workplaces. In: Bethan L. Davies, Michael Haugh, and Andrew John Merrison (eds.), Situated Politeness. London: Continuum, 27-52.

Holmes, Janet, Meredith Marra, and Mariana Lazzaro-Salazar. 2017. Negotiating the tall poppy syndrome in New Zealand workplaces: Women leaders managing the challenge. Gender and Language 11(1): 1-29.

Holmes, Janet, Meredith Marra, and Bernadette Vine. 2011. Leadership, Discourse and Ethnicity. Oxford: Oxford University Press.

Holmes, Janet, Meredith Marra and Bernadette Vine. 2012. Politeness and impoliteness in ethnic varieties of New Zealand English. Journal of Pragmatics 44(9): 1063-1076.

Holmes, Janet, Meredith Marra, and Bernadette Vine. 2019. Telling stories: analysing Māori and Pākehā workplace narratives. Journal of the Royal Society of New Zealand, DOI: 10.1080/o3036758.2019.1653329. Vol 49, TUIA25o Supplement: 104-117.

Holmes, Janet and Nicky Riddiford. 2009. Talk at work: Interactional challenges for immigrants. In: Vijay K. Bhatia, Winnie Cheng, Bertha Du-Babcock and Jane Lung (eds.), Language for Professional Communication: Research, Practice and Training. Hong Kong: The Hong Kong Polytechnic University, 217-235.

Holmes, Janet and Maria Stubbe 2003/2015. Power and Politeness in the Workplace. London: Routledge.

Holmes, Janet and Bernadette Vine. Forthcoming. Workplace research and applications in real world contexts: The case of the Wellington Language in the Workplace Project. In: Geert Jacobs and Sofie Decock (eds.), What Counts as Data? On the "Ins" of Business and Professional Discourse Research and Training. Palgrave.

Huygens, Ingrid. 20o6. Discourses for decolonisation: Affirming Maori authority in New Zealand workplaces. Journal of Community \& Applied Social Psychology 16: 363-378.

Jautz, Sabine. 2013. Thanking Formulae in English. Explorations Across Varieties and Genres. Amsterdam: John Benjamins.

Kasper, Gabriele and Shoshana Blum-Kulka (eds.). 1993. Interlanguage Pragmatics. New York: Oxford University Press.

Marra, Meredith. 2005. "Whiter than white": Constructing ethnic and professional identity in a Maori workplace. Presentation, Language in the media, Leeds University, Leeds 12-14 September 2005. 
Marra, Meredith. 2008. Recording and analyzing talk across cultures. In: Helen Spencer-Oatey (ed.), Culturally Speaking: Managing Rapport through Talk Across Cultures, 2nd edn. London: Continuum, 304-321.

Marra, Meredith. 2012. Disagreeing without being disagreeable: Negotiating workplace communities as an outsider. Journal of Pragmatics 44: 1580-90.

Marra, Meredith, Brian W. King, and Janet Holmes. 2013. Trivial, mundane or revealing? Food as a lens on ethnic norms in workplace talk. Language and Communication 34: 46-55.

Mead, Hirini Moko. 2016. Tikanga Māori: Living by Māori Values. Revised edn. Wellington: Huia \& Te Whare Wananga o Awanuiarangi.

Menard-Warwick, Julia. 2013. English Language Teachers on the Discursive Faultlines: Identities, Ideologies and Pedagogies. Bristol: Multilingual Matters.

Metge, Joan. 1995. New Growth from Old: The Whanau in the Modern World. Wellington: Victoria University Press.

Metge, Joan and Patricia Kinloch. 1978. Talking Past Each Other: Problems of Cross-Cultural Communication. Wellington: Victoria University Press.

Morrison, Anthea and Janet Holmes. 2003. Eliciting refusals: A methodological challenge. Te Reo 46: 47-66.

Philips, Susan U. 1972. Participant structures and communicative competence: Warm Springs children in community and classroom. In: Courtney B. Cazden, Vera P. John and Dell Hymes (eds.), Functions of Language in the Classroom. New York: Columbia Teachers Press, 370-394.

Pohl, Gabriela. 2004. Cross-cultural pragmatic failure and implications for language teaching. Second Language Learning \& Teaching 4(2): 91-112.

Prebble, John. 2007. Workplace communication for skilled migrants: English for professional purposes VUW ELIN941. Language in the Workplace Occasional Papers 6.

Rüegg, Larssyn. 2014. Thanks responses in three socio-economic settings: A variational pragmatics approach. Journal of Pragmatics 71: 17-30.

Salmond, Anne. 1974. Rituals of encounter among the Maori: Sociolinguistic study of a scene. In: Richard Bauman and Joel Sherzer (eds.), Explorations in the Ethnography of Speaking. Cambridge: Cambridge University Press, 192-212.

Salmond, Anne. 1975a. Hui: A study of Maori Ceremonial Gatherings. Wellington: Reed. Salmond, Anne. 1975b. Mana makes the man: A look at Maori oratory and politics. In: Maurice Bloch (ed.) Political Language and Oratory in Traditional Society. London: Academic Press, 45-64.

Schneider, Klaus and Anne Barron (eds.). 2008. Variational Pragmatics: A Focus on Regional Varieties in Pluricentric Languages. Amsterdam: John Benjamins.

Schnurr, Stephanie and Janet Holmes. 20og. Using humour to do masculinity at work. In: Neal R. Norrick and Delia Chiaro (eds.), Humor in Interaction. Amsterdam: John Benjamins, 101-123. 
Schnurr, Stephanie, Meredith Marra and Janet Holmes. 2007. Being (im)polite in New Zealand workplaces: Māori and Pākehā leaders. Journal of Pragmatics 39(4): 712-29. Schnurr, Stephanie and Olga Zayts. 2017. Language and Culture at Work. London: Routledge.

Smith, Linda Tuhiwai. 1999. Decolonising Methodologies: Research and Indigenous Peoples. London: Zed Books.

Spencer-Oatey, Helen and Jianyu Xing. 200o. A problematic Chinese business visit to Britain: Issues of face. In: Helen Spencer-Oatey (ed.), Culturally Speaking Managing Rapport through Talk Across Cultures. London: Continuum, 272-288.

Thornton, Agathe. 1985. Two features of oral style in Māori narrative. The Journal of the Polynesian Society 94: 149-176.

Thornton, Agathe. 1999. Māori oral literature: As seen by a classicist. Revised edn. Dunedin, New Zealand: Otago University Press.

Trosborg, Anna (ed.). 2010. Pragmatics Across Languages and Cultures. Berlin: Walter de Gruyter.

Turnbull, William. 2001. An appraisal of pragmatic elicitation techniques for the social psychological study of talk: The case of request refusals. Pragmatics 11:31-61.

Vine, Bernadette. 2019. Context matters: Exploring the influence of norms, values and contexts on a Māori male manager. Journal of Cross-Cultural Psychology $5^{\circ}$ : 1182-1197.

Vine, Bernadette, Janet Holmes and Meredith Marra. 2012. Mentoring migrants: Facilitating the transition to the New Zealand workplace. In: Holger Limberg and Miriam A. Locher (eds.), Advice in Discourse. Amsterdam: John Benjamins, 145-165.

Wilson, Carla. 2001. Review of "Decolonising Methodologies: Research and Indigenous Peoples" by Linda Tuhiwai Smith, 1999, Zed Books, London. Social Policy Journal of New Zealand 17: 214-217.

Woolard, Kathryn A. 1998. Introduction: Language ideology as a field of inquiry. In: Bambi B. Schiefflin, Kathryn A. Woolard and Paul V. Kroskrity (eds.), Language Ideologies: Practice and Theory. Oxford: Oxford University Press, 3-47.

Wodak, Ruth. 2008. Controversial issues in feminist critical discourse analysis. In: Kate Harrington, Lia Litosseliti, Helen Sauntson and Jane Sunderland (eds.), Gender and Language Research Methodologies. London: Palgrave, 193-210.

Zhu, Hua and Claire Kramsch. 2016. Symbolic power and conversational inequality in intercultural communication. Special Issue of Applied Linguistics Review 7(4): $375^{-529}$. 